\title{
Hidropisia fetal não-imune: efeito da presença de cromossomopatia na mortalidade fetal e neonatal
}

\section{Nonimmune hydrops fetalis: effect of the presence of chromosomopathy on fetal and neonatal mortality}

Autor: Alessandra Fritsch

Orientador: Prof. Dr. José Antônio A. Magalhães

Dissertação de Mestrado apresentada ao Programa de Pós-Graduação em Medicina: Ciências Médicas da Universidade Federal do Rio Grande do Sul (UFRGS), em 8 de novembro de 2004.

E-mail: alessandrafritsch@terra.com.br - Fone: (51) 9911-4308

Objetivo: avaliar a mortalidade fetal e neonatal entre fetos com hidropisia fetal não-imune (HFNI), comparando os casos com e sem cromossomopatia associada. Métodos: foi realizado um estudo de coorte histórico e contemporâneo entre janeiro de 1992 e dezembro de 2003, envolvendo gestantes com o diagnóstico de HFNI encaminhadas ao setor de Medicina Fetal do Hospital de Clínicas de Porto Alegre (HCPA). A todas as pacientes foi oferecida a realização de um protocolo de investigação: ultra-sonografia morfológica, amniocentese (citogenética, infecções e erros inatos do metabolismo), ecocardiografia fetal e necropsia nos casos de óbito fetal ou neonatal. Resultados: foram estudados 43 casos. Os pacientes foram divididos em dois grupos: 29 pacientes $(67,4 \%)$ sem cromossomopatia e 14 pacientes $(32,6 \%)$ com cromossomopatia. A mortalidade fetal foi significativamente maior no gru- po com cromossomopatia. Dos 29 hidrópicos sem cromossomopatia, houve 13 mortes intra-útero $(44,8 \%)$. Já, dos 14 hidrópicos com cromossomopatia, $13(92,9 \%)$ morreram intra-útero $(p=0,003)$. Em relação à mortalidade neonatal, dos 16 nativivos hidrópicos sem cromossomopatia, $12(75 \%)$ morreram no período neonatal. Houve apenas um nativivo hidrópico com cromossomopatia. Este evoluiu ao óbito no período neonatal. Conclusão: os fetos portadores de HFNI e cromossomopatia têm uma chance maior de morrerem intra-útero do que os fetos com HFNI sem cromossomopatia associada. Daí a importância da investigação completa destes fetos visando ao diagnóstico precoce e à definição do prognóstico desta gestação.

PALAVRAS-CHAVE: Hidropisia fetal não-imune; Cromossomopatia; Mortalidade fetal; Mortalidade neonatal

Resumo de Tese

\section{Efetividade da assistência pré-natal sobre a mortalidade materna e a morbi-mortalidade neonatal no Brasil}

\section{Effectiveness of prenatal care on maternal mortality and neonatal morbimortality in Brazil}

Autor: Bruno Gil de Carvalho Lima

Orientadora: Prof ${ }^{\text {. Dr }}{ }^{\mathrm{a}}$. Maria da Conceição Nascimento Costa

Dissertação apresentada ao Programa de Pós-Graduação em Saúde Coletiva da Universidade Federal da Bahia para a obtenção do grau de Mestre em Saúde Comunitária (Epidemiologia), em 18 de outubro de 2004.

O modelo tradicional de assistência pré-natal (APN) vem sendo questionado. Estratégias com menos consultas incluindo estritamente ações de efetividade comprovada estão sendo testadas. No Brasil, trabalhos apontam falhas do conteúdo da assistência. Com o objetivo de analisar a evolução da utilização da APN brasileira e sua relação com a mortalidade materna e neonatal, estudouse uma série temporal da utilização de consultas, de 1996 a 2000, em 22 capitais, testando-se ainda sua correlação com baixo peso ao nascer (BPN) e prematuridade. Os Sistemas de Informações do Ministério da Saúde foram as fontes dos dados. Não foi encontrada correlação entre utilização do pré-natal e os indicadores investigados. Discutem-se as deficiências técnicas da APN como possiveis explicações da não efetividade para redução dos desfechos desfavoráveis. Objetivando estimar o impacto da APN sobre a saúde materno-infantil, foi realizado um estudo ecológico, utilizando-se capitais como unidades de análise e dados do SINASC de 2000. Calcularam-se razões de prevalência (RP) e frações preveniveis de BPN e prematuridade entre gestantes com mais de seis e seis ou menos consultas. Procedeu-se, ainda, à análise estratificada da associação entre APN e BPN para avaliação de possiveis covariáveis. Encontraram-se RP de 1,3 a 2,8 para baixo peso e 1,5 a 4,1 para prematuridade, com frações preveniveis de até 64,4 e 75,7\%, respectivamente. Em capitais específicas, prematuridade, educação, estado civil e primigestação foram modificadoras de efeito dessa associação. A APN mostrou-se uma ação de saúde efetiva na redução de desfechos gestacionais mórbidos, mas novas investigações incluindo modelagem são necessárias.

PALAVRAS-CHAVE: Assistência pré-natal; Efetividade; Mortalidade materna; Mortalidade neonatal; Baixo peso ao nascer; Prematuridade 